\title{
Explanation on the Abnormal Behavior during the Nanoindentation Holding Stages by Amplifying Oscillation
}

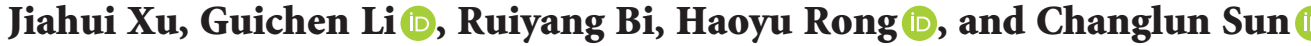 \\ School of Mines, Key Laboratory of Deep Coal Resource Mining, Ministry of Education of China, \\ China University of Mining and Technology, Xuzhou 221116, Jiangsu, China \\ Correspondence should be addressed to Guichen Li; liguichen@cumt.edu.cn
}

Received 16 August 2020; Accepted 5 January 2022; Published 18 January 2022

Academic Editor: Francesco Colangelo

Copyright (c) 2022 Jiahui Xu et al. This is an open access article distributed under the Creative Commons Attribution License, which permits unrestricted use, distribution, and reproduction in any medium, provided the original work is properly cited.

Recently, the holding states of nanoindentation experiments have been widely used to analyze the time-dependent deformations of various rocks, and the dynamic mechanical analysis (DMA) method seems to be more applicable than the quasi-static mechanical analysis (QMA) method when the influence of creep deformation on mechanical properties of rocks was analyzed. However, the former method causes an abnormal behavior during the creep holding stages that was not clearly interpreted.2 Consequently, in this study, by amplifying the oscillation of the DMA method, the mechanical mechanism of this phenomenon was explained. Experimental results confirm that the rheological deformation of rocks consists of the creep deformation (depth increasing) and the elastic aftereffect deformation (depth decreasing) during the creep time with small oscillation; once the elastic aftereffect deformation exceeds the creep deformation, the abnormal behavior can be observed. Besides, some other abnormal behaviors might be found for other rock materials when the DMA method with different oscillations is used, which illustrates the complexity and limitation of applying this method. Thus, the QMA method was recommended to investigate the above questions in future studies.

\section{Introduction}

In the deep underground, the rheological phenomenon is the most important mechanical property of geomaterials, which negatively impacts the safety of engineering structure [1-3], coalbed methane (CBM) and shale gas production [4-6], geological disposal repository effectiveness [7], and so on. As a result, to enhance the understanding of this phenomenon is of importance for deep rock mechanics. The most popular method to investigate the creep behavior of geomaterials is based on in-scale core samples, which is time-consuming and challenging to obtain enough intact specimens $[3,8,9]$.

Recently, the holding states of nanoindentation experiments have been widely used to analyze the time-dependent deformations of biomaterials [10], metals and alloys [11, 12], ceramics $[13,14]$, polymers and composites [15-18], types of cement $[19,20]$, and even crystals $[21,22]$. Besides, the estimation of the macrofracture toughness of minerals and rocks is given in [23], while the analysis of the micromechanical properties of mineral crystal grains is becoming more and more extensive [24-26]. All those above mean that the experimental technique was a robust way to conduct creep tests. And it was convenient to obtain the sizeable samples from broken rock blocks since the size requirement was just about one centimeter. Consequently, the nanoindentation technique starts being adopted in the field of geomaterials' rheology, especially for shale in the petroleum and gas industries, helping reveal some undiscovered problems at the macroscale. Taking gas shale formations as examples, the role of the organic matter $(\mathrm{OM})$ in gas shale is "the dominant creeping phase," which drives the creep rate [27]. Analogously, the hard minerals in shale collected from Bakken formation have much smaller creep deformation than that of softer ones [28]. The quasi-static mechanical analysis (QMA) method and the dynamic mechanical analysis (DMA) method that was regarded as two basic approaches to conduct nanoindentation creep tests [29] 
were respectively used in above the two articles. And for other geomaterials obtained in coal mines, such as coal, mudstone, and sandstone, the quasi-static mechanical analysis method was also widely used to reveal their timedependent deformation phenomenon [25, 30].

However, this technique also causes some debate in the field of rock mechanics. Using the quasi-static nanoindentation method, prior research results presented that "as the creep time increases, the Young's modulus, hardness, and fracture toughness decreases" [31], which means that the depth of indents increases with holding time. While, for the convenience of conducting a continuous and accurate measurement, the DMA method was used, showing that "the dynamic mechanical properties such as storage modulus and hardness were found to first decrease and then increase after the holding time exceeds a certain value" [32]. "Elastic recovery during the holding period" and "stress relaxation" were considered as the reasons for this abnormal behavior [32], which cannot explain why the quasi-static nanoindentation method yields normal results [31] and brings much debate on whether the DMA method is suitable to discuss the rheological responses of rocks. Consequently, further explanation for different results is deemed to be made to help comprehend the rheological characteristics of the DMA method and propagate the application of the nanoindentation technique in rock mechanics.

Thus, in this article, considering that the only difference between the two methods is that only the DMA method has small oscillations, the method named oscillation amplification was adopted to try to explain the abnormal behavior. This paper was structured as follows: first, the oscillation amplification method was clearly introduced (Section 2); second, in Section 3, the experimental results were given in detail to illustrate the existence of elastic aftereffect beforehand; third, the discussions in Section 4 calculated the nanoindentation rheological strain-time curves, determined the constitutive model of rock nanoindentation rheological behaviors, and analyzed several situations that might be encountered if the DMA method was used in the future study. In conclusion, the rheological deformation of rock investigated by using the DMA method is very complicated, showing the limitation of using this method.

\section{Oscillation Amplification Method}

In order to overcome the main limitation of the quasi-static mechanical analysis (QMA) method in which the hardness and modulus values can only be calculated at the initial part of the unloading curve, the dynamic mechanical analysis (DMA) method with quasi-static force being kept constant and small oscillation being superimposed was proposed and used [28], as shown in the left part of Figure 1(a). However, as mentioned above, prior study results found an abnormal behavior when the holding time exceeds a certain value by using this experimental method. To try to explain this in terms of rock mechanics, in the right part of Figure 1(a), the method to amplify the small oscillation was schematically illustrated.

In short, the deformation response of a small oscillation can be replaced by a holding period at the maximum load followed by another holding period after unloading to a small load (minimum load) value. The whole creep time has numerous alternately occurring maximum load and minimum load-holding periods. The load-holding periods at the maximum load are seated together, first (stage $b-c$ ) and then the periods at the minimum load happen together next (stage $d-e$ ). The two holding periods are connected by a ramp unloading process (stage $c-d$ ) in practice. The experimental protocol in Figure 1(b) further amplifies the different rheological responses during stage $b-c$ and stage $d-e$ by setting the maximum load at $50 \mathrm{mN}$ and then unloading to $10 \%$ of it (minimum load). Besides, to calculate the hardness and elastic modulus of materials, before both load-holding periods, the typical nanoindentation experiment (stage $o-a$ ) was also conducted in this study. It consists of the loading segment, holding segment of $5 \mathrm{~s}$, and unloading segment with the loading and unloading rates of $100 \mathrm{mN} / \mathrm{min}$.

Many previous study results displayed that the deformation during the load-holding period at $10 \%$ of the maximum load originates from temperature drift when the rheological properties of other materials were investigated, such as thin $\mathrm{Cu}$ film [33] and polycrystalline Al film [22]. However, this method implicitly assumed that the timedependent deformation during this period was ignored [34] and nanoindentation experimental systems have low resolutions. Thus, to not only consider the time-dependent deformation during the load-holding period at $10 \%$ of the peak load but also to avoid the influence of this error of equipment-temperature drift, the thermal equilibrium time of the Aton Pharr NHT3 system equiped with Berkovich indenter was more than $1 \mathrm{~h}$, and compensations were autumatically formulated [35]. Both the thermal equilibrium and compensations were done previously based on other materials and the thermal drift also reaches much less than $0.01 \mathrm{~nm} / \mathrm{s}$ [35], since we found the deformation of rocks (shale, mudstone, and coal) during the holding period of $10 \%$ of the maximum load is time-dependent rather a linear increase [36], which is too large to be ignored. After compensating, three random indentations were made on each rock sample to research the time-dependent deformation characteristics.

\section{Results}

Taking shale, mudstone, and coal, derived from China's coal mines as examples [37], three nanoindentation tests labeled sample-1, -2 , and -3 following the protocol in Figure 1(b) were made on the random locations on each sample. The hardness and elastic modulus of three nanoindentation tests on each sample was computed by using the Oliver-Pharr method through stage $o-a$ in Figure 1(b) [34]. Calculated results show that the mechanical properties of different positions on each sample are various. For example, the hardness of shale-1, shale-2, and shale- 3 are $532.71 \mathrm{MPa}$, $523.53 \mathrm{MPa}$, and $801.05 \mathrm{MPa}$; and that for mudstone-1, mudstone-2, and mudstone- 3 are $598.46 \mathrm{MPa}, 376.08 \mathrm{MPa}$, and $217.32 \mathrm{MPa}$; and for coal-1, coal-2, and coal-3 are 388.43 $\mathrm{MPa}$, $317.08 \mathrm{MPa}$, and $153.88 \mathrm{MPa}$. The elastic modulus of coal and rock increases linearly with their 


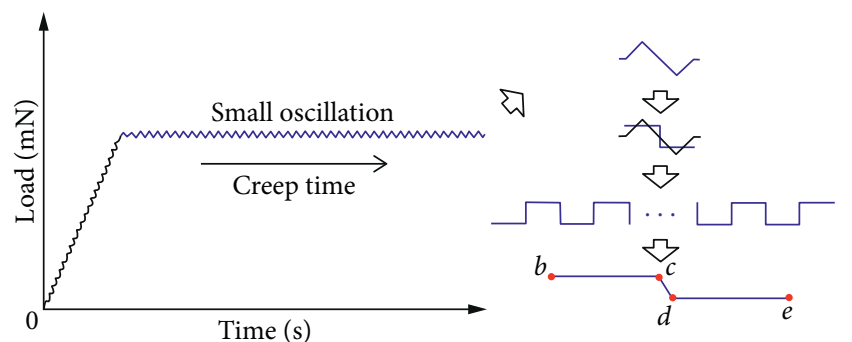

(a)

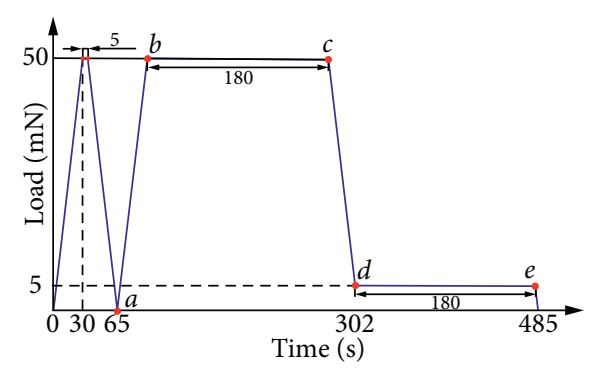

(b)

Figure 1: (a) The schematic illustration of the oscillation amplification method and (b) the experimental protocol.

hardness [38]. Obviously, at the mesoscale, geomaterials are typical heterogeneous materials, consisting of various mineralogical constituents in different positions.

The deformations during stage $b-c(-\mathrm{C}$ with solid symbols) and that during stage $d-e$ (-E with open symbols) of shale, mudstone, and coal are given in Figures 2(a), 2(b), and 2(c), respectively, where the deformation-time curves of all tests on different surface locations start from 0 . The increasing depth is positive deformation. Besides, as shown in Figure 2, just like the hardness and elastic modulus in different positions on each sample are different, the deformations during stage $b-c(-\mathrm{C})$ and that during stage $d-e$ (-E) are different, which not only shows that the rheological properties of different positions are various but also illustrates that these displacements of stage $d-e(-\mathrm{E})$ are not caused by thermal drift.

For shale, mudstone, and coal samples, during the period of stage $b-c$, the indentation depth or deformation is rapidly growing at first and then slows down over time. Throughout stage $d$-e, indentation depth decreases with time for mudstone, coal, and shale-3. However, for shale-1 and shale-2, when the holding time exceeds a certain value, the indentation depth begins to increase. During the holding period of $50 \mathrm{mN}$, the deformations or depths of indentations are not abnormal by using the quasi-static nanoindentation method [31]; while during the holding period of $5 \mathrm{mN}$ is negative and decrease with time or firstly decline then slightly increase. The creep deformation during the holding period of the maximum load was widely detected and investigated as mentioned above, but there are limited studying results to discuss the depth decreasing phenomenon after unloading to a small value, probably causing some confusion of the time-dependent deformation during the unloading period in any form, such as thermal drift [33] and small oscillation [32]. Consequently, understanding this phenomenon is of significance.

\section{Discussions}

4.1. Nanoindentation Rheological Strain-Time Curves. In previous nanoindentation tests, only the creep deformations were observed as an increase in depth during a hold period at the maximum load in the load-displacement data for a range of materials [29]. However, this method was out of the framework of rock rheology and limited the analysis of rheological properties of rocks to some extent. Thus, converting the nanoindentation depth-time data to the strain-time data is necessary. For the nanoindentation rheological experiments, the stress and strain rates can be expressed as $[39,40]$

$$
\begin{aligned}
& \dot{\varepsilon}=\frac{\mathrm{d} h(t)}{\mathrm{d} t} \frac{1}{h(t)}, \\
& \sigma=\frac{\beta F}{h^{2}(t)},
\end{aligned}
$$

where $\sigma$ is the stress, MPa; $\dot{\varepsilon}$ is the strain rate, $\mathrm{s}^{-1} ; h(t)$ is the indentation depth changing with time, $\mathrm{nm} ; t$ is the time, $s$; and $\beta$ is the geological constant of indenter (for Berkovich indenter, $\beta=0.0407$ [40]).

In rock rheology, the creep deformation can be recorded during the constant load time, and after unloading to a small load value or 0 , elastic aftereffect deformation happens $[41,42]$.

4.1.1. Nanoindentation Creep Stage (Stage b-c). In this stage, the indentation depth $(h(t))$ increases with time. Equation (2) was integrated to get the nanoindentation creep strain $\varepsilon_{C}(t)$

$$
\varepsilon_{C}(t)=\ln \frac{h(t)}{h_{b}},
$$

where $\varepsilon_{C}(t)$ is the nanoindentation creep strain, and $h_{b}$ is the indentation depth at the point of $b, \mathrm{~nm}$.

4.1.2. Nanoindentation Elastic Aftereffect Stage (Stage d-e). In stage $d$-e, the indentation depth decreases with time during the initial part, meaning that the deformation is timedependent. The elastic aftereffect is a phenomenon of delayed recovery of the elastic deformation [41, 42]. The strain expression in the elastic aftereffect stage can also be obtained by integrating equation (2). In this process, it should be noted that the elastic aftereffect strain is a negative value.

$$
\varepsilon_{E}(t)=\ln \frac{h(t)}{h_{d}},
$$

where $\varepsilon_{E}(t)$ is the elastic aftereffect strain and $h_{d}$ is the indentation depth at the point of $d, \mathrm{~nm}$. 


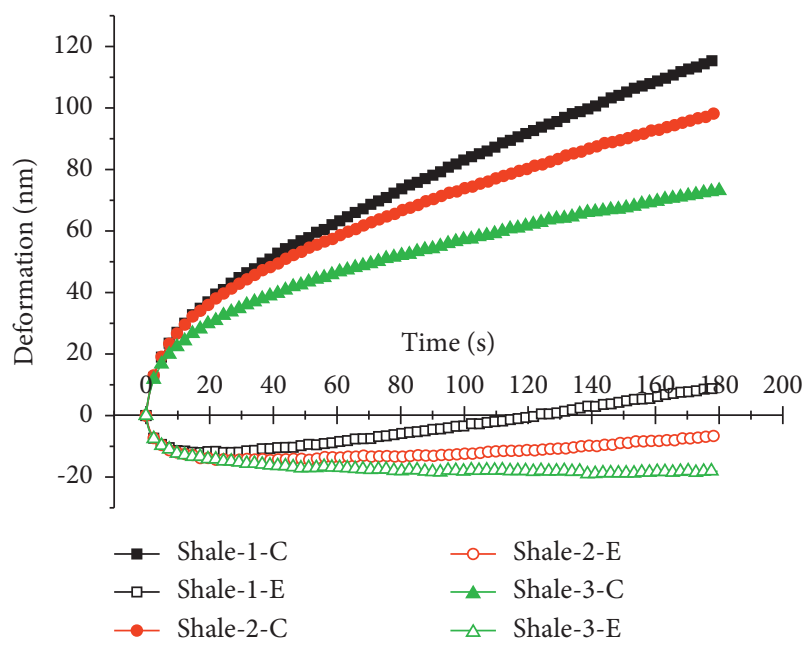

(a)

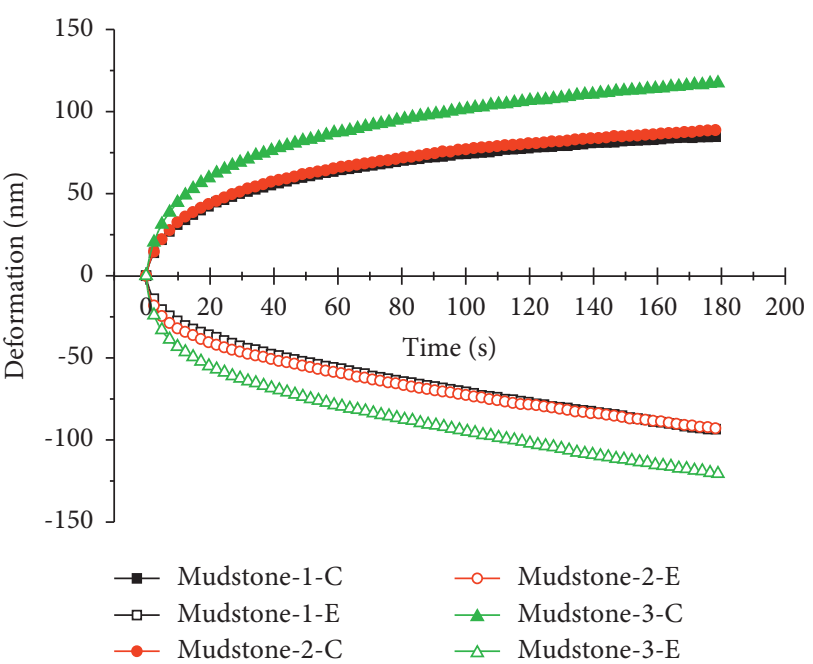

(b)

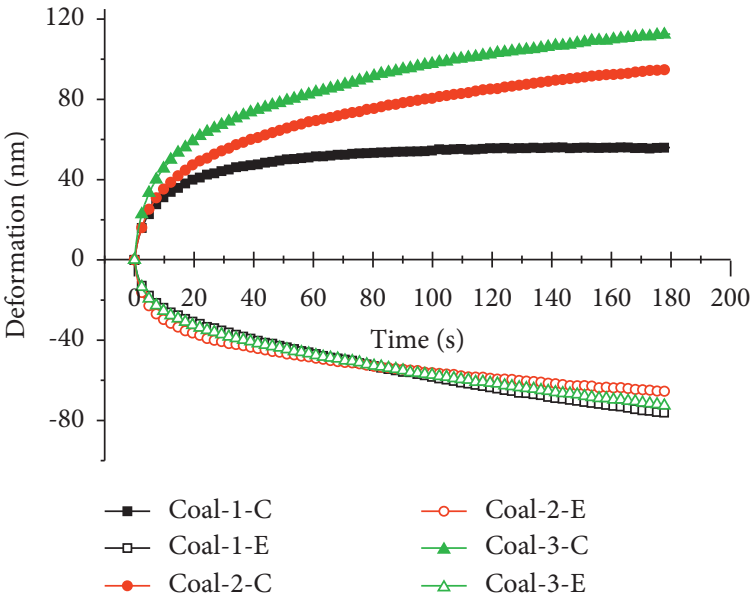

(c)

Figure 2: Deformation-time curves of (a) shale, (b) mudstone, and (c) coal during stage $b-c(-\mathrm{C})$ and that during stage $d$-e (-E) starting from 0 .

Therefore, according to the typical nanoindentation rheological experiment process (Figure 1(b)) and the above nanoindentation rheological theory, the depth-time data of the nanoindentation experiments can be converted into the strain-time curves consisting of creep and elastic aftereffect stages, as shown in Figure 3 taking shale-3, mudstone-3, and coal-3 as examples.

Both the nanoindentation creep and elastic aftereffect curves include two phases: the transition deformation phase and the stable deformation phase. During the transition deformation phase, at first, the creep strain increases sharply with time, and then the strain rate slows down; during the stable deformation phase, the creep strain increases linearly at an almost constant rate. After unloading to $10 \%$ of the maximum load, the elastic strain gradually recovers with the first fast strain rate and then a small constant rate during the whole period of elastic aftereffect for shale-3, mudstone-3, and coal-3. However, for shale-1, the strain increases during the stable deformation phase of elastic aftereffect, where its rheological mechanism was not explained, too.

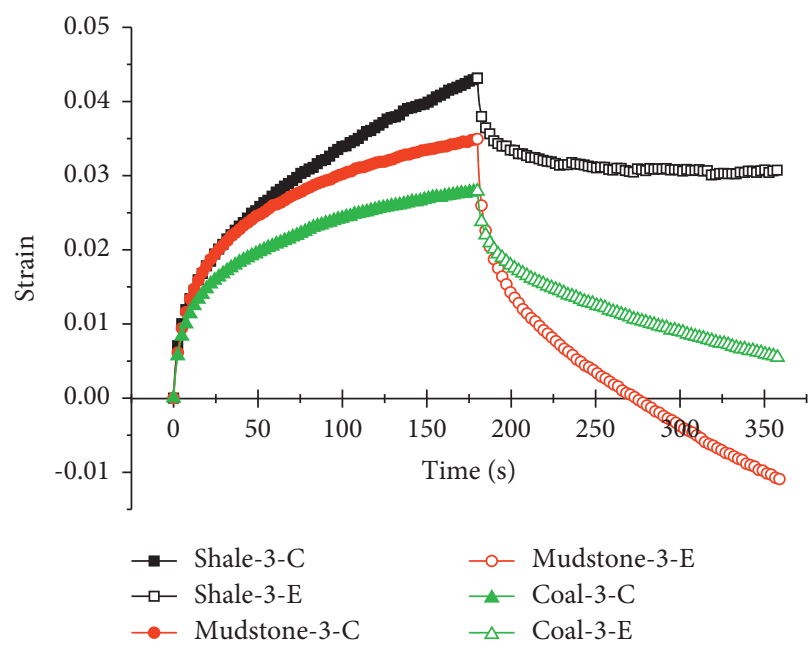

FIgURE 3: Nanoindentation rheological strain-time curves of shale-3, mudstone-3, and coal-3 including creep (-C) and elastic aftereffect (-E). 
Consequently, discussing the constitutive model of nanoindentation rheological curves is of importance for making sure the deformation characteristic during both loadholding periods.

\subsection{Nanoindentation Rheological Constitutive Model.} Considering the viscoelastic properties of shale, mudstone, and coal samples and the rheological deformation properties of nanoindentation experiments. The simplified Burgers model was tried to be utilized to fit the nanoindentation experimental data, and this model is schematically presented in Figure 4.

For the viscous element and Kelvin model in series, the stress and strain relationship can be expressed as

$$
\begin{aligned}
& \varepsilon=\varepsilon_{1}+\varepsilon_{2}, \\
& \sigma=\sigma_{1}=\sigma_{2} .
\end{aligned}
$$

And for the Kelvin model with Hooke element and viscous element in parallel, the stress and strain relationship can be expressed as

$$
\begin{gathered}
\varepsilon_{1}=\varepsilon_{11}=\varepsilon_{12}, \\
\sigma_{1}=\sigma_{11}+\sigma_{12},
\end{gathered}
$$

where $\sigma_{1}$ and $\varepsilon_{1}$ are the stress and strain of the Kelvin model, $\sigma_{2}$ and $\varepsilon_{2}$ are the stress and strain of the viscous element on the left part, $\sigma_{11}$ and $\varepsilon_{11}$ are the stress and strain of the Hooke element in the Kelvin model, and $\sigma_{12}$ and $\varepsilon_{12}$ are the stress and strain of the viscous element in the Kelvin model.

The creep equation has been given previously, but the equation of elastic aftereffect without complete unloading needs to be further derived here for direct application in the future study. According to equations (5) and (6), the equations of creep curve and elastic aftereffect curve of the simplified Burgers model is presented as

$$
\begin{aligned}
\varepsilon_{C}(t)= & \frac{\sigma_{0}}{\eta_{2}} t+\frac{\sigma_{0}}{E_{1}}\left(1-e^{-E_{1} / \eta_{1} t}\right), \\
\varepsilon_{E}(t)= & \frac{\sigma_{1}}{E_{1}}-\frac{\sigma_{1}}{\eta_{2}}\left(t-t_{1}\right) \\
& +\left(\varepsilon_{1}-\frac{\sigma_{1}}{E_{1}}+\frac{\sigma_{1}}{\eta_{2}}\left(t-t_{1}\right)\right) e^{-E_{1} / \eta_{1}\left(t-t_{1}\right)},
\end{aligned}
$$

where $\sigma_{0}$ is the constant stress during the creep stage, and $\sigma_{1}$ is the constant stress during the stage of the elastic aftereffect.

The whole rheological process can be described by a piecewise function consisting of a creep equation (equation (7)) and an elastic aftereffect equation (equation (8)). To verify the utilization of the creep equation, first, equation (7) was used to fit the experimental data derived from stage $b-c$, as shown in Figure 5.

In Figure 5, the fitting black, red, and blue solid curves for (a) shale, (b) mudstone, and (c) coal have coefficients of determination $(R)$ larger than 0.9863 , proving that the creep equation of the simplified Burger's model can perfectly characterize the creep behavior of shale, mudstone, and coal samples. Then, the elastic aftereffect equation (equation (8)) was used to fit the experimental data derived from stage $d-e$. Since nanoindentation elastic aftereffect curves have different initial strain values, the fitting results are separately analyzed. And Figures 6-8 give the fitting results of shale, mudstone, and coal, respectively.

The experimental data of shale- 1 and shale- 2 can also be perfectly fitted by the elastic aftereffect equation of the simplified Burgers model even though their deformations or depths decrease at first and then increase with time, differing with other experimental results. During the period of elastic aftereffect time, deformations consist of time-dependent elastic recovery of the Kelvin model (right part in Figure 4) in the simplified Burgers model and the creep deformation of the viscous element (left part in Figure 4) in it. Thus, the different behaviors of shale- 1 and shale- 2 are caused by the creep strain rate exceeding the elastic recovery rate during this period.

4.3. Possible Situations of Using the Dynamic Mechanical Analysis (DMA) Method. The time-dependent characteristics of rocks during the period of the constant peak load time and the period of unloading to $10 \%$ of the peak loads were analyzed in section 4.1 and 4.2 by using the theories of rock rheology. During the period of creep time in the DMA method (Figure 1(b)), the deformation of small oscillation consists of creep deformation to increase the indentation depth and elastic aftereffect deformation causing time-dependent elastic recovery with small creep deformation. Comparison of the magnitude of creep deformations and elastic recovery deformations during this whole period can reveal the mechanism of abnormal behavior during the nanoindentation holding stage if the creep deformation and elastic aftereffect deformation happen at the same time. Taking shale-2, mudstone-2, and coal-1 as examples, the black lines with squares show the positive creep deformation, and the red lines with circles show the elastic aftereffect deformation with small creep deformation under the assumption that both of them are starting at 0 and develop simultaneously. Thus, the deformation throughout this period can be obtained by adding them to represent the creep time with small oscillations (Figure 1(a)), shown by the blue line with a triangle. Figure 9 gives additional results.

For an experiment named shale-2, the creep strain is much larger than that of elastic aftereffect strain during the whole process, which illustrates that the total deformation increases with holding time. For mudstone-2, during the first 10 seconds, the elastic aftereffect deformation is slightly larger than that of the creep deformation; the middle 130 seconds record a contrary result, and during the last 40 seconds, the elastic aftereffect deformation is slightly greater than that of the creep deformation again. And for Coal-1, the total deformation of the first 87 seconds is positive while the last 93 seconds have a negative total deformation. Consequently, the abnormal behavior that the creep deformation increases with time followed by a reduction of deformation with time in the article entitled "Abnormal behavior during nanoindentation holding stage: Characterization and 


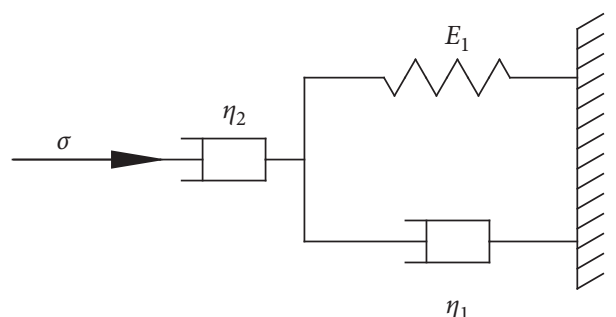

FIgURE 4: The simplified Burgers model without an elastic element in series.

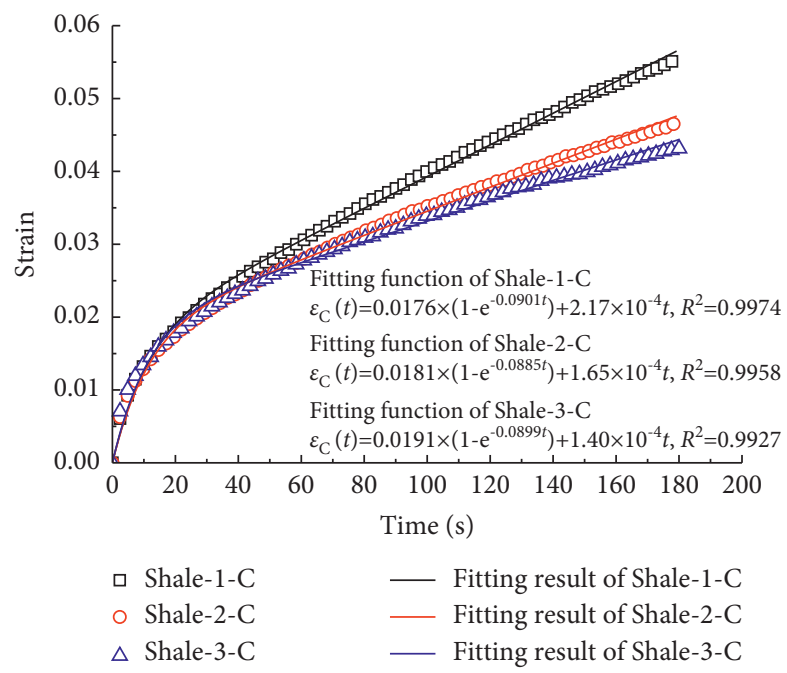

(a)

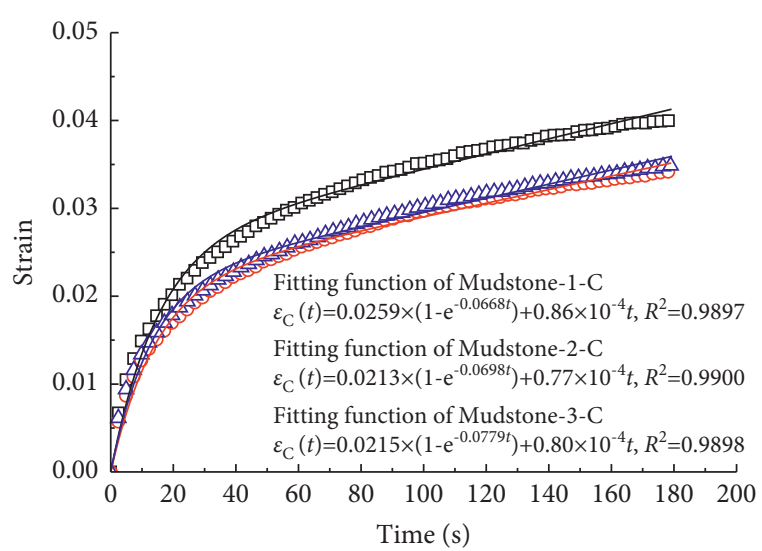

a Mudstone-1-C Fitting result of Mudstone-1-C

o Mudstone-2-C - Fitting result of Mudstone-2-C

$\triangle$ Mudstone-3-C $\_$Fitting result of Mudstone-3-C

(b)

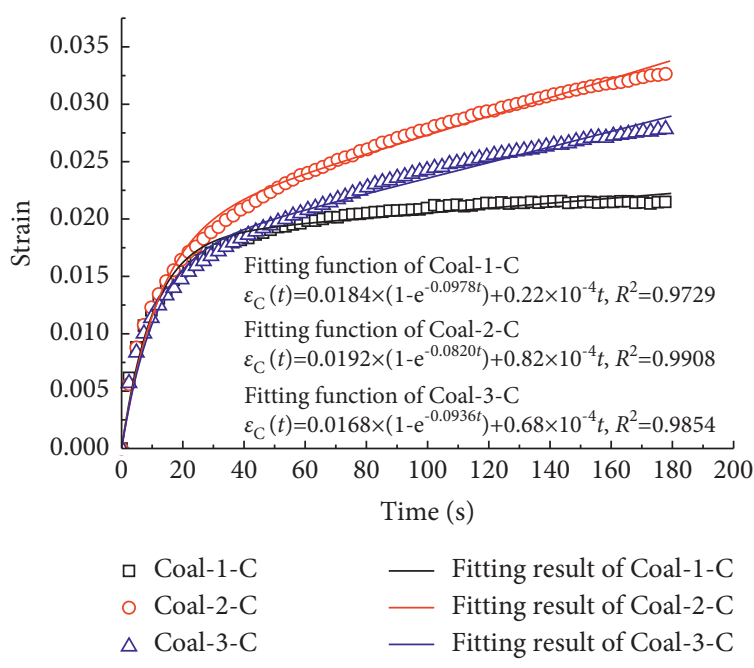

(c)

FIGURE 5: Fitting results of creep curves of (a) shale, (b) mudstone, and (c) coal by using the creep equation of the simplified Burgers model.

explanation" published in 2019 (173) in the Journal of Petroleum Science and Engineering [32] is consistent with the characteristic of coal-1, which is just one situation of DMA method to discuss the influence of holding time on the mechanical properties of materials. For other materials, as shale and mudstone studied in this article, other situations may be encountered during creep time with small oscillation. 


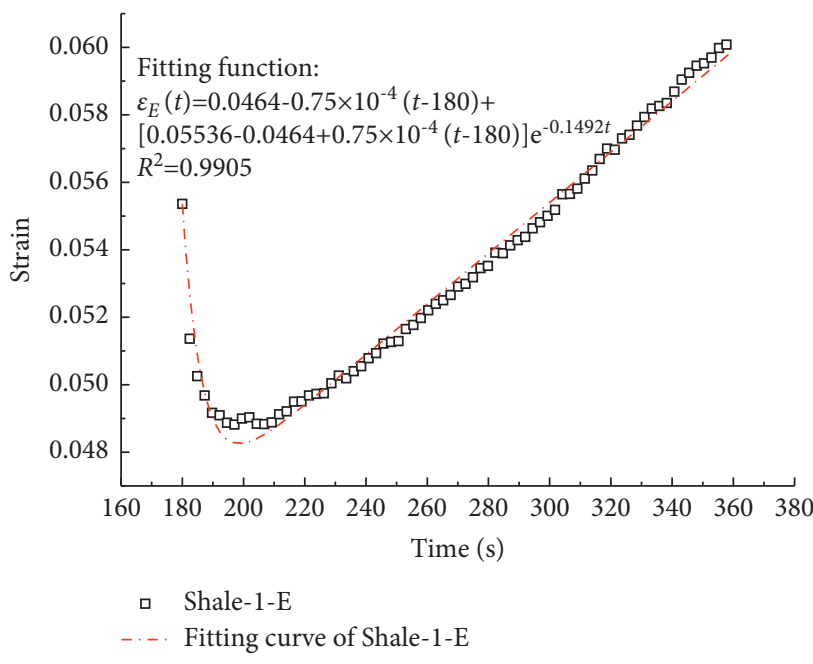

(a)

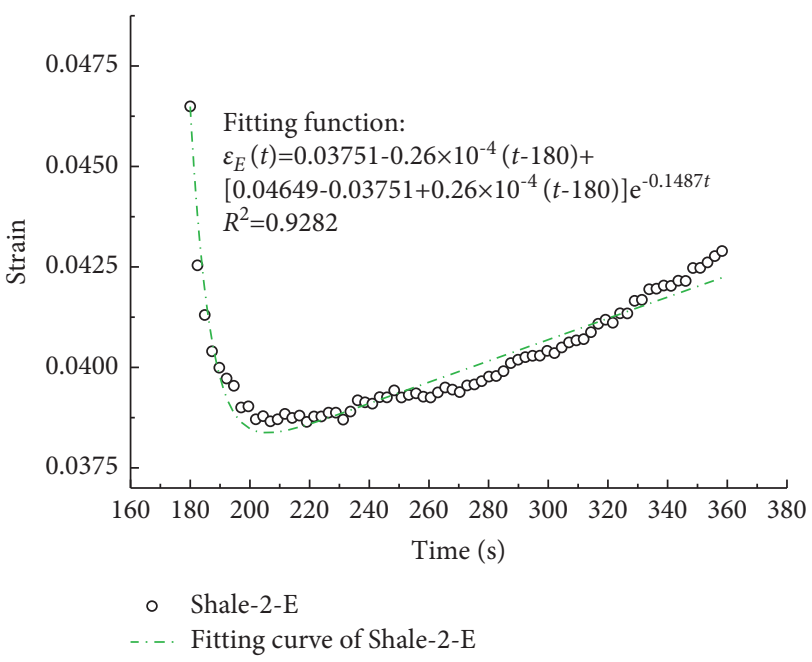

(b)

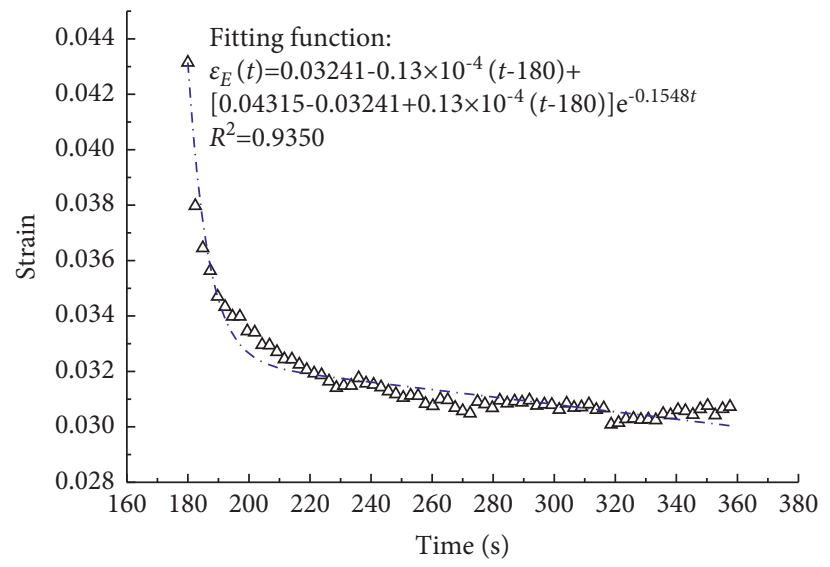

$\Delta \quad$ Shale-3-E

-.-. Fitting curve of Shale-3-E

(c)

FIGURE 6: Fitting results of elastic aftereffect curves of (a) shale-1, (b) shale-2, and (c) shale- 3 by using the elastic aftereffect equation of the simplified Burgers model.

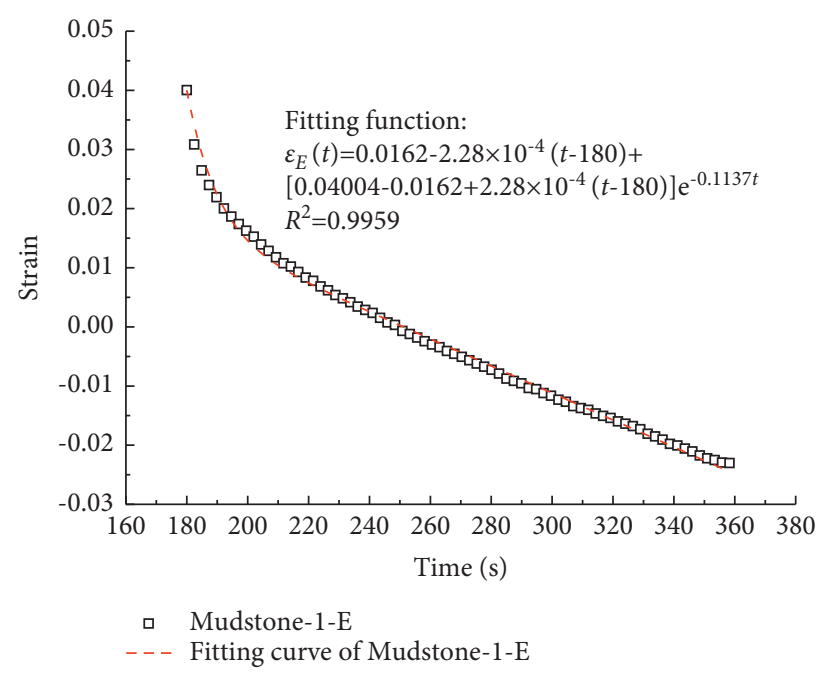

(a)

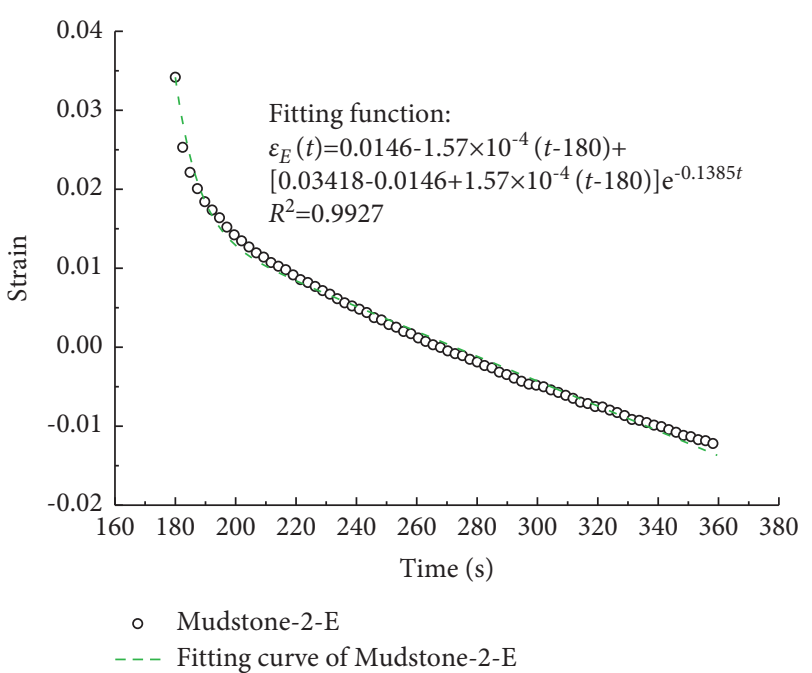

(b)

Figure 7: Continued. 


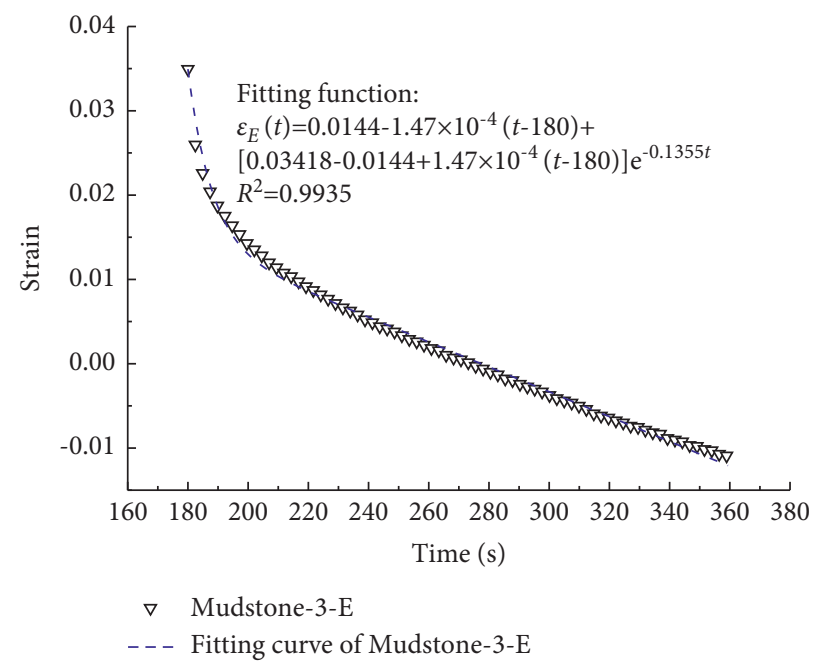

(c)

Figure 7: Fitting results of elastic aftereffect curves of (a) mudstone-1, (b) mudstone-2, and (c) mudstone-3 by using the elastic aftereffect equation of the simplified Burgers model.

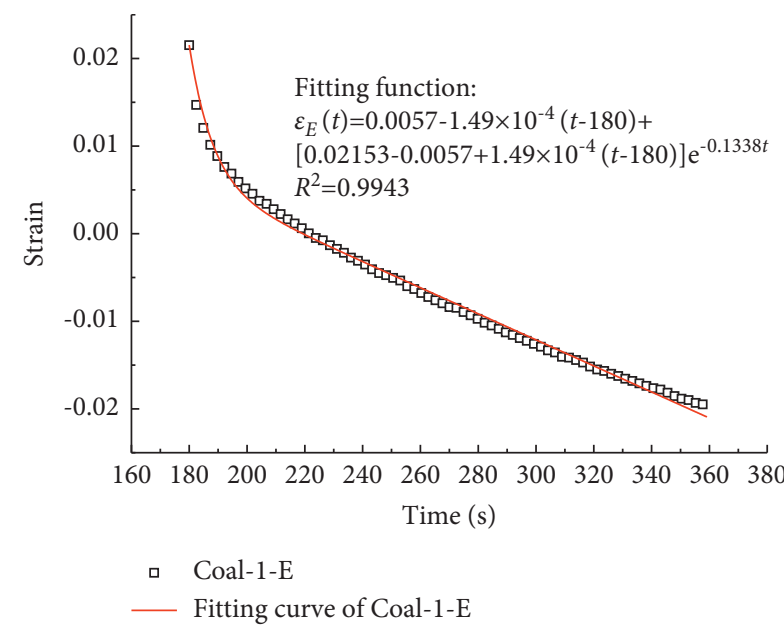

(a)

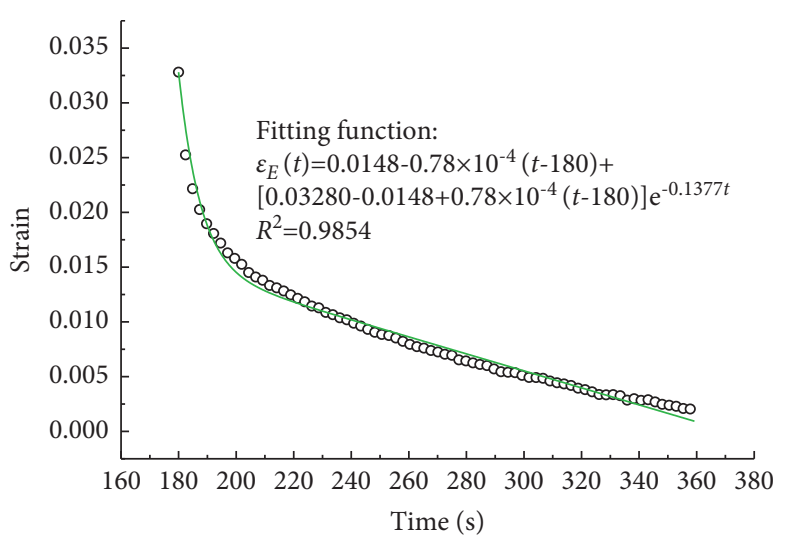

- Coal-2-E

Fitting curve of Coal-2-E

(b)

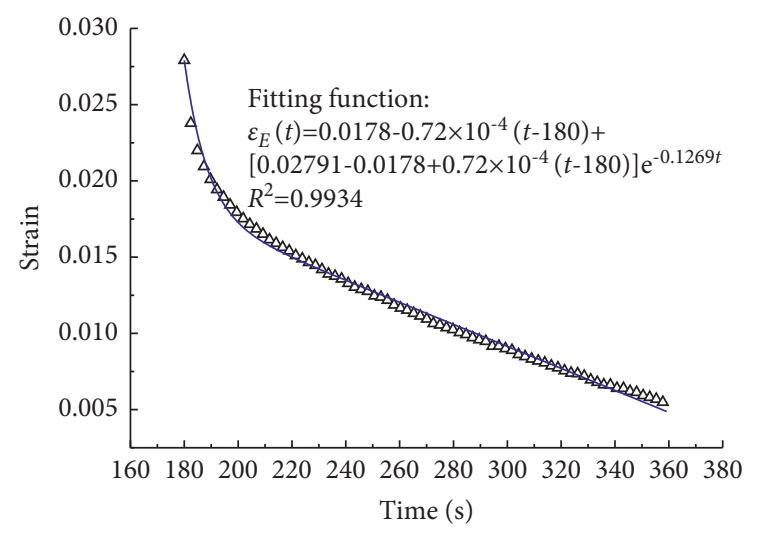

$\Delta \quad$ Coal-3-E

__ Fitting curve of Coal-3-E

(c)

FIGURE 8: Fitting results of elastic aftereffect curves of (a) coal-1, (b) coal-2, and (c) coal-3 by using the elastic aftereffect equation of the simplified Burgers model. 


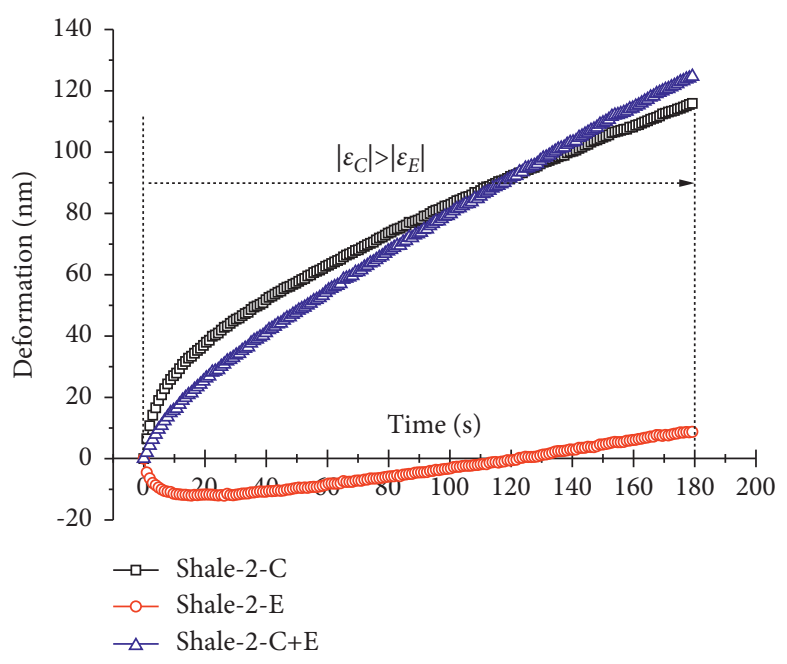

(a)

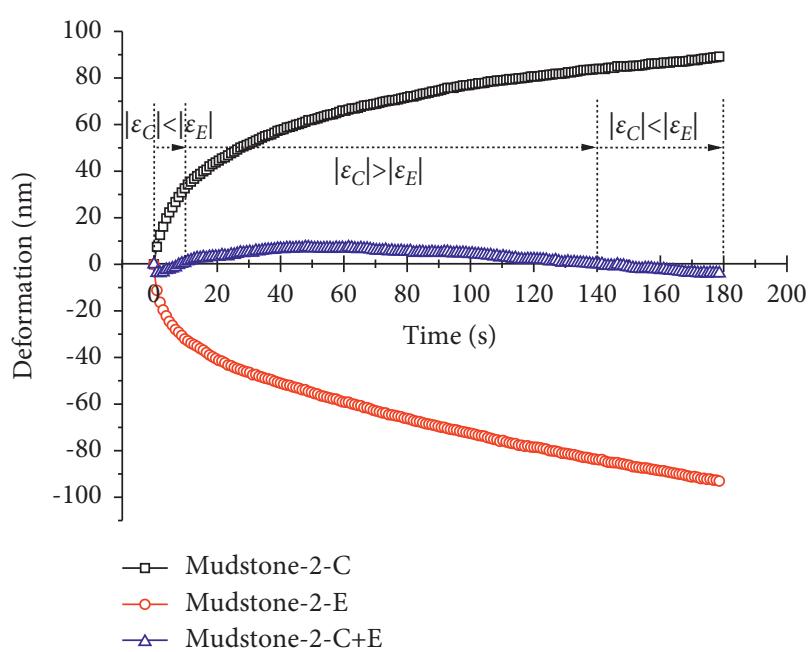

(b)

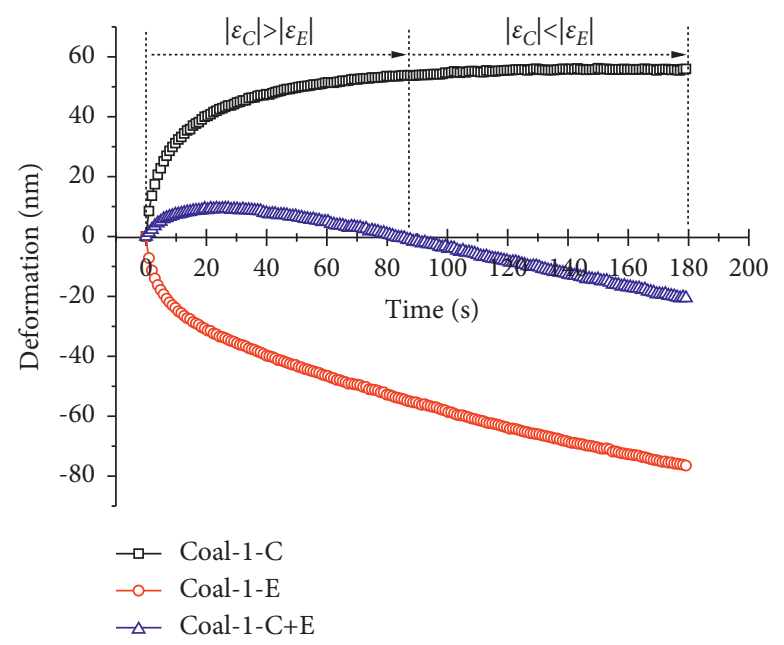

(c)

Figure 9: The overall strain of (a) shale-2, (b) mudstone-2, and (c) coal-1 by using the simplified Burgers model.

\section{Conclusions}

One of the highlights in the article is the dedicated discussion and explanation of the influence of nanoindentation elastic aftereffect on creep deformation when the dynamic mechanical analysis (DMA) method is used by adopting the method of oscillation amplification. Drawing the conclusions as follows:

(1) Through analyzing the nanoindentation strain-time data, the shale has apparent rheological behavior while the abnormal situation appears that the strain increases during the stable deformation phase of the elastic aftereffect.

(2) The simplified Burgers model was able to fit the nanoindentation experimental data well. After that, the reason of the different behaviors of shale could be drawn as the creep strain rate exceeding the elastic recovery rate during elastic aftereffect.
(3) Under the influence of holding time, the mechanical properties of shale, mudstone, and coal are different. The elastic aftereffect deformation and creep aftereffect deformation of different materials have different performances, resulting in the small oscillation that appears in the creep stage.

Research results explain the abnormal behavior observed in an article entitled "Abnormal behavior during nanoindentation holding stage: Characterization and explanation" and published in 2019 (173) in the Journal of Petroleum Science and Engineering, which is that the elastic aftereffect deformation exceeds the creep deformation during the creep time in Figure 1(a). In turn, researchers will consider the practicability of the DMA method to discuss the influence of creep time on mechanical properties in future studies, and the quasi-static mechanical analysis (QMA) method is recommended for accuracy. 


\section{Data Availability}

No data were used to support this study.

\section{Conflicts of Interest}

The authors declare that there are no conflicts of interest.

\section{Acknowledgments}

The work presented in this paper was supported by the projects of "the Postgraduate Research and Practice Innovation Program of Jiangsu Province (KYCX21_2384)," "National Natural Science Foundation of China (52174089)," and "the Fundamental Research Funds for the Central Universities (2020ZDPY0221)”.

\section{References}

[1] T. T. Cai, Z. C. Feng, and Y. L. Jiang, "An improved hardening-damage creep model of lean coal: a theoretical and experimental study," Arabian Journal of Geosciences, vol. 11, no. 20, 2018.

[2] A. Sainoki and H. S. Mitri, "Numerical investigation into pillar failure induced by time-dependent skin degradation," International Journal of Mining Science and Technology, vol. 27, no. 4, pp. 591-597, 2017.

[3] R. Hou, Y. Shi, L. Xu, J. Fu, and K. Zhang, "Evaluating longterm strength and time to failure of sandstone with different initial damage," Advances in Civil Engineering, vol. 2020, Article ID 7149148, 15 pages, 2020.

[4] N. N. Danesh, Z. Chen, L. D. Connell, M. S. Kizil, Z. Pan, and S. M. Aminossadati, "Characterisation of creep in coal and its impact on permeability: an experimental study," International Journal of Coal Geology, vol. 173, pp. 200-211, 2017.

[5] H. Sone and M. D. Zoback, "Time-dependent deformation of shale gas reservoir rocks and its long-term effect on the in situ state of stress," International Journal of Rock Mechanics and Mining Sciences, vol. 69, pp. 120-132, 2014.

[6] H. W. Zhou, L. J. Wang, T. L. Rong, L. Zhang, W. G. Ren, and T. Su, "Creep-based permeability evolution in deep coal under unloading confining pressure," Journal of Natural Gas Science and Engineering, vol. 65, pp. 185-196, 2019.

[7] Z. B. Liu, S. Y. Xie, J. F. Shao, and N. Conil, "Effects of deviatoric stress and structural anisotropy on compressive creep behavior of a clayey rock," Applied Clay Science, vol. 114, pp. 491-496, 2015.

[8] Y. Song, L. Zhang, H. Yang, J. Ren, and Y. Che, "Experimental study on the creep behavior of red sandstone under low temperatures," Advances in Civil Engineering, vol. 2019, Article ID 2328065, 9 pages, 2019.

[9] S. Yang, N. Zhang, X. W. Feng, and J. Kan, "Experimental investigation of the creep behaviour of coal by monitoring changes of acoustic properties," Applied Sciences-Basel, vol. 8, no. $4,2018$.

[10] L.-H. He and M. V. Swain, "Nanoindentation creep behavior of human enamel," Journal of Biomedical Materials Research Part A, vol. 91a, no. 2, pp. 352-359, 2009.

[11] G. Feng and A. H. W. Ngan, "Creep and strain burst in indium and aluminium during nanoindentation," Scripta Materialia, vol. 45, no. 8, pp. 971-976, 2001.

[12] S. Soare, S. J. Bull, A. G. O’Neil, N. Wright, A. Horsfall, and J. M. M. dos Santos, "Nanoindentation assessment of aluminium metallisation; the effect of creep and pile-up," Surface and Coatings Technology, vol. 177-178, pp. 497-503, 2004.

[13] J. Zhang, C. Wang, F. Yang, and C. Du, "Nanoindentation creep behavior of enamel biological nanocomposites," RSC Advances, vol. 4, no. 77, pp. 41003-41009, 2014.

[14] E. Liu, H. Wang, G. Xiao, G. Yuan, and X. Shu, "Creep-related micromechanical behavior of zirconia-based ceramics investigated by nanoindentation," Ceramics International, vol. 41, no. 10, pp. 12939-12944, 2015.

[15] H. Lu, B. Wang, J. Ma, and H. Viswanathan, "Measurement of creep compliance of solid polymers by nanoindentation," Mechanics of Time-dependent Materials, vol. 7, no. 3-4, pp. 189-207, 2003.

[16] B. D. Beake, G. A. Bell, W. Brostow, and W. Chonkaew, "Nanoindentation creep and glass transition temperatures in polymers," Polymer International, vol. 56, no. 6, pp. 773-778, 2007.

[17] Y. Zhao, H. Q. Li, Z. L. Zhang, J. Cellia, S. Percecb, and F. Rena, "Nanoindentation study of time-dependent mechanical properties of ultra-high-molecular-weight polyethylene (UHMWPE) at different temperatures," Polymer Testing, vol. 91, 2020.

[18] T. Pertin, G. Minatchy, M. Adoue, and A. Flory, "Investigation of nanoindentation as a fast characterization tool for polymer degradation study," Polymer Testing, vol. 81, 2020 L. Romana.

[19] J. Nemecek, "Creep effects in nanoindentation of hydrated phases of cement pastes," Materials Characterization, vol. 60, no. 9, pp. 1028-1034, 2009.

[20] C. A. Jones and Z. C. Grasley, "Short-term creep of cement paste during nanoindentation," Cement and Concrete Composites, vol. 33, no. 1, pp. 12-18, 2011.

[21] K. Sangwal, P. Gorostiza, and F. Sanz, "Atomic force microscopy study of nanoindentation creep on the (100) face of $\mathrm{MgO}$ single crystals," Surface Science, vol. 446, no. 3, pp. 314-322, 2000.

[22] F. Wang, P. Huang, and K. Xu, "Strain rate sensitivity of nanoindentation creep in polycrystalline $\mathrm{Al}$ film on silicon substrate," Surface and Coatings Technology, vol. 201, no. 9-11, pp. 5216-5218, 2007.

[23] Z. Zhou, B. Lei, X. Cai, and Y. Rui, "Estimating macrofracture toughness of sandstone based on nanoindentation," Geofluids, vol. 2021, Article ID 6621643, 10 pages, 2021.

[24] C. Sun, G. Li, M. E. Gomah, J. Xu, and H. Rong, "Experimental Investigation on the Nanoindentation Viscoelastic Constitutive Model of Quartz and Kaolinite in Mudstone," vol. 8, pp. 925-937, 2021, International Journal of Coal Science \& Technology.

[25] C. Sun, G. Li, M. E. Gomah, J. Xu, and Y. Sun, "Creep characteristics of coal and rock investigated by nanoindentation," International Journal of Mining Science and Technology, vol. 30, no. 6, pp. 769-776, 2020.

[26] C. Yang, Y. Xiong, J. Wang, and Y. Li, "Mechanical characterization of shale matrix minerals using phase-positioned nanoindentation and nano-dynamic mechanical analysis," International Journal of Coal Geology, vol. 229, 2020.

[27] M. Slim, S. Abedi, L. T. Bryndzia, and F. J. Ulm, "Role of organic matter on nanoscale and microscale creep properties of source rocks," Journal of Engineering Mechanics, vol. 145, no. 1, 2019.

[28] K. Liu, M. Ostadhassan, B. Bubach, R. Dietrich, and V. Rasouli, "Nano-dynamic mechanical analysis (nano-DMA) of creep behavior of shales: Bakken case study," Journal of Materials Science, vol. 53, no. 6, pp. 4417-4432, 2017. 
[29] A. C. Fischer-Cripps, "A simple phenomenological approach to nanoindentation creep," Materials Science and Engineering a-Structural Materials Properties Microstructure and Processing, vol. 385, no. 1-2, pp. 74-82, 2004.

[30] C. Sun, G. Li, J. Xu, and H. Rong, "Rheological characteristics of mineral components in sandstone based on nanoindentation," Chinese Journal of Rock Mechanics and Engineering, vol. 40, no. 1, pp. 77-87, 2021.

[31] K. Liu, M. Ostadhassan, and B. Bubach, "Application of nanoindentation to characterize creep behavior of oil shales," Journal of Petroleum Science and Engineering, vol. 167, pp. 729-736, 2018.

[32] K. Liu, M. Ostadhassan, X. Xu, and B. Bubach, "Abnormal behavior during nanoindentation holding stage: characterization and explanation," Journal of Petroleum Science and Engineering, vol. 173, pp. 733-747, 2019.

[33] F. Wang and K. W. Xu, "An investigation of nanoindentation creep in polycrystalline $\mathrm{Cu}$ thin film," Materials Letters, vol. 58, no. 19, pp. 2345-2349, 2004.

[34] W. C. Oliver and G. M. Pharr, "An improved technique for determining hardness and elastic modulus using load and displacement sensing indentation experiments," Journal of Materials Research, vol. 7, no. 6, pp. 1564-1583, 1992.

[35] Z. Cao and X. Zhang, "Nanoindentation creep of plasmaenhanced chemical vapor deposited silicon oxide thin films," Scripta Materialia, vol. 56, no. 3, pp. 249-252, 2007.

[36] T. Chudoba and F. Richter, "Investigation of creep behaviour under load during indentation experiments and its influence on hardness and modulus results," Surface and Coatings Technology, vol. 148, no. 2-3, pp. 191-198, 2001.

[37] C. Sun, G. Li, S. Zhang, J. Xu, and H. Yang, "Mechanical and heterogeneous properties of coal and rock quantified and mapped at the microscale," Applied Sciences, vol. 10, no. 1, 2020.

[38] C. Sun, G. Li, M. E. Gomah et al., Experimental Investigation on the Mechanical Properties of Crushed Coal Samples Based on the Nanoindentation Technique, Journal of China Coal Society, vol. 46, no. S02, China, 2020.

[39] M. J. Mayo and W. D. Nix, "A micro-indentation study of superplasticity in $\mathrm{Pb}, \mathrm{Sn}$, and $\mathrm{Sn}-38$ wt\% $\mathrm{Pb}$," Acta Metallurgica, vol. 36, no. 8, pp. 2183-2192, 1988.

[40] S. A. Hackney, K. E. Aifantis, A. Tangtrakarn, and S. Shrivastava, "Using the Kelvin-Voigt model for nanoindentation creep in Sn-C/PVDF nanocomposites," Materials Science and Technology, vol. 28, no. 9-10, pp. 1161-1166, 2012.

[41] J. Sun, "Rock rheolocical mechanics and its advance in engineering applications," Chinese Journal of Rock Mechanics and Engineering, vol. 26, no. 6, pp. 1081-1106, 2007.

[42] M. Cai, M. He, and D. Liu, Rock Mechanics and Engineering, Science Press, Beijing, China, Second edition, 2013. 